\title{
Truth-Predicates Still Not like Pronouns: a Reply to Salis
}

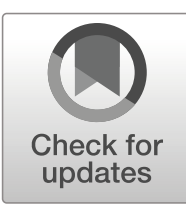

\section{Arvid Båve ${ }^{1}$}

Received: 18 October 2018 / Revised: 12 March 2019 / Accepted: 15 April 2019 /

Published online: 15 May 2019

(C) The Author(s) 2019

\begin{abstract}
I here respond to Pietro Salis's objections against my original critique of the Prosentential Theory of Truth (PT). In addition, I clarify some points regarding the relationship between anaphoric relationships and "general semantic notions" like "equivalence", "consequence", and "sameness of content", and make some further points about (PT)'s ability gto explain pragmatic and expressive features of "true".
\end{abstract}

Keywords Truth $\cdot$ Prosentential $\cdot$ Grover $\cdot$ Belnap $\cdot$ Brandom $\cdot$ Salis $\cdot$ Anaphor $\cdot$ Pronoun

Pietro Salis's paper, "The generality of anaphoric deflationism" (2019) is devoted to criticizing the objections against the Prosentential Theory of Truth (PT) that I raised in Båve (2009a). I will here try to sustain my original criticisms, sometimes through modifications motivated by Salis's criticisms.

The original prosententialists were Grover et al. (1975), but their theory was substantially developed by Brandom (1994). A common thread (among many differences) is that the word 'true' is taken to function in a way similar to anaphoric expressions like pronouns. For instance, the sentence, 'That's true!', as uttered in response to some statement, is taken to have that preceding statement as its anaphoric antecedent, just as 'Mary' is the antecedent of 'she' in 'If Mary is absent, then she is probably sick'.

My original case against (PT) consisted mainly of "Material Criticisms" and "Principal Criticisms" (2009a: §II and §III, respectively). The first consist of a multitude of arguments to the effect that 'true' does not work like paradigmatic anaphoric expressions (like pronouns), neither in the way prosententialists allege, nor any other way. The second type of criticism is that even if 'true' were similar to paradigmatic anaphoric expressions like pronouns (so that the "material criticisms" would not apply), saying so would merely be an "idle analogy" with no explanatory power. Rather, given an account of the functioning of anaphoric expressions, one would be able to derive from (PT) a

Arvid Båve

arvidbave@gmail.com

1 Department of Philosophy, Stockholm University, Götgatan 92A, 11862 Stockholm, Sweden 
theory of the functioning of "true' lacking any notions of "anaphor", "antecedent", etc. I took this to show that there is nothing "essentially proformal" about 'true'.

I will not describe all of the specific claims about particular constructions made by the prosententialists that I discussed in the original paper, but only those discussed by Salis, and I will do so consecutively and with my own comments and replies interspersed as we march along.

Salis first takes issues with my objections against Brandom's treatment of sentences like,

\section{(1) Goldbach's conjecture is true.}

Brandom takes (1) to indirectly inherit its content from.

\section{(2) Any even number is the sum of two primes.}

About the expression 'is true' in (1), Brandom says, "[i]t applies to a term that is a sentence nominalization or that refers to or picks out a sentence tokening. It yields a prosentence that has that tokening as its anaphoric antecedent" (1994: 305). I argued that 'true', as Brandom characterizes it, differs from other, paradigmatic proforms, since no other proform has an antecedent which is determined by way of reference (in the sense of denotation, rather than anaphoric cross-reference) in this way.

Salis objects that, "Båve here tendentiously reads the connection between the antecedent and the prosentence in terms of reference, rather than in terms of content inheritance. It is not clear why he thinks that content inheritance could be granted only by a non-deflationary notion of reference" (2019: 513). But, firstly, Brandom himself describes the relation between the antecedent and the prosentence as involving "referring" or "picking out", by which he means denotation, rather than anaphoric cross-reference. Thus, Salis's suggestion is not faithful to Brandom.

A further note about my use of "paradigmatic": a paradigmatic anaphor is an uncontroversial case of a anaphor. Everyone should agree that whereas, e.g., pronouns fit this descriptions, 'true' does not. But I am not presupposing that all anaphors are paradigmatic anaphors. That would be wildly question-begging against prosententialists. It is nevertheless important, for determining how plausible it is to say that 'true' is anaphoric, to see whether it resembles paradigmatic anaphors.

Could we suppose, though, as Salis seems to suggests, that we instead take the relation between (1) and (2) to involve only anaphoric cross-reference, or "content inheritance"? (This would be a modification of Brandom's view.) First of all, it is clear that on Brandom's account, (2) is determined as the antecedent of (1) only via the singular term, 'Goldbach's conjecture'. ${ }^{1}$ So, could we suppose that (2) becomes the antecedent of (1) in virtue of this term inheriting its content from (2), rather than by denotationally referring to it? No, for 'Goldbach's conjecture' cannot by any stretch be taken to inherit its content from (2). If it did, then they would have to have the same content (in this context, anyway). ${ }^{2}$ But, surely,

\footnotetext{
$\overline{1}$ Salis actually takes Brandom to claim that (1) itself "picks out a sentence tokening" (2019: 508). But the quote from Brandom above makes clear that it is "Goldbach's conjecture", not (1) in its entirety, that picks something out. This is also in line with the commonplace idea that only singular terms refer to things, and sentences never do.

2 The two obviously do not have the same meaning. Two tokenings can, however, have the same content in a context, which is why it is suitable here to speak of inheritance of content, rather than meaning.
} 
they don't. They belong to different syntactic categories, one being a singular term and the other being a sentence. They also differ markedly from uncontroversial cases of content inheritance via anaphoric dependency. This is more easily seen if we switch examples from (1) to.

\section{(3) The third sentence in the Bible is true.}

If (3) is supposed to inherit its content from the third sentence in the Bible, its content should be necessarily and a priori equivalent with the content of the third sentence in the Bible. This holds in paradigmatic cases of anaphoric dependency. More precisely, for every token paradigmatic proform $p$ with antecedent $a$, a sentence token $s$ containing $p$ will have a content necessarily and a priori equivalent with the content expressed by a sentence differing from $s$ only in containing $a$ in place of $p$. If a token of 'thusly' has a token of 'by running' as its antecedent, then the contents expressed by the relevant tokens of 'She got there by running' and 'She got there thusly' are a priori and necessarily equivalent (indeed, they would seem to be identical). This clearly does not hold in the case of (3) and the third sentence of the Bible, however. (Note that this argument also targets Brandom's claim that (2) is the antecedent of (1).) In view of these observations, it seems that 'Goldbach's conjecture' in (1) cannot be taken to inherit its content from (2) via anaphoric dependency. Thus, the only relevant way in which one can relate to (2) in one's use of 'Goldbach's conjecture' is via denotational reference, as Brandom himself claims.

Another conceivable retreat for Brandom is a modification of his account on which 'Goldbach's conjecture' has as its sole function to determine an antecedent from which the content of (1) is inherited, and that the singular term manages to do so without denoting (2) (or some token of it). ${ }^{3}$ But this proposal of course raises the question how 'Goldbach's conjecture' latches on to (2) at all. These two expressions can scarcely be taken to be related the way 'she' is related to 'Mary' in 'If Mary is not here, she must be sick'. For 'Goldbach's conjecture' would have to be able to latch on to (2) also in contexts in which (2) has not been uttered, and in which, indeed, neither speaker nor hearer even knows that Goldbach's conjecture is. And claiming that 'Goldbach's conjecture' determines (2) as the antecedent of (1) while holding that there is no explanation of how it does so seems unsatisfactory.

There may seem to be a way of reconciling Brandom's and Salis's claims about (1) and (2), namely, by claiming that this particular case of denotational reference is included among the anaphoric relations. However, this merely amounts to widening the notion of "anaphoric relations". This terminological change would not save the account from the objection that "anaphoric relations", in this special sense, are different from anaphoric relations, as we normally conceive of them.

The reader may at this point have worried about a dubious assumption underlying Brandom's treatment of (1), namely, that 'Goldbach's conjecture' refers to a particular sentence tokening. It is certainly more natural and plausible to take 'Goldbach's conjecture' to refer to the proposition that any even number is the sum of two primes. This is of course a further problem with Brandom's view. And note that it cannot easily be modified so as to conform to the more plausible account of the referent of

\footnotetext{
${ }^{3}$ A reviewer for this journal proposes that this is what Brandom actually means. I prefer my above interpretation of Brandom, but this exegetical issue is orthogonal to the main point, which is that Brandom's theory faces difficulties on both interpretations.
} 
'Goldbach's conjecture'. For Brandom cannot very well hold that 'Goldbach's conjecture' refers to the proposition and continue to hold that (2) is the antecedent of (1). For if he did, then the relationship between (1) and (2) would be even less direct, and (1) would now differ even more starkly from paradigmatic cases of anaphor-antecedent relationships. To wit, the alleged antecedent (2) would now be determined, not by being the referent of 'Goldbach's conjecture', but by being a sentence expressing the proposition that is its referent. Surely, no other proform relates to its antecedents in this way.

To sum up: Brandom cannot explain the meaning of (1) merely by reference to anaphoric relations or to "content inheritance". In order to explain how (2) becomes the antecedent, he must say (as he actually does) that this happens through 'Goldbach's conjecture' denotationally referring to (2). And my original point was that no other proform works this way, which in turn casts doubt on (PT).

Against this, it may objected that since Brandom gives an anaphoric account of (denotational) reference, it is not a problem for him to take anaphoric dependencies to involve denotational reference. But, on the contrary, it does not matter which view of reference Brandom adopts, since it remains the case that paradigmatic proforms do not determine antecedents by way of denotation. This is so whether or not we adopt an "anaphoric" account of denotation. Just as it is crucial to keep the denotation/anaphoric cross-reference distinction apart from the substantial/deflationary distinction, we must also keep the relationship between anaphors and antecedent apart from the relationship that holds between "Snow is white" and 'Snow is white'. The former always holds between linguistic expressions whereas the latter only sometimes does (as in the example just given). But the latter also holds between 'Aristotle' and Aristotle, the flesh-and-blood human, and he could never be an antecedent or an anaphoric expression.

What about Salis's complaint that I read Brandom as appealing to a non-deflationary notion of reference? I did complain, in an ad hominem aside, which was not part of the argument we have been discussing, that Brandom "makes use of a non-deflationary notion of reference, contrary to his professed commitment to eschew such representational notions" (2009a: 305).

I was wrong, I believe, to add the qualification "non-deflationary" here. For none of what Brandom says about (1) precludes him from adopting a deflationary account of denotational reference. But the real problem, which still stands, is that Brandom appeals to denotational reference at all, contrary to his stated commitment to "turn the explanatory tables on the representationalist tradition" (1994: 136), i.e., of giving an account of contentfulness, etc., in terms of inference rather than representational notions like reference. It does not help that he gives a "deflationist" or "anaphoric" account of denotational reference. At best, he could change his overarching goal to explaining meaning/content without appealing to a nondeflationary notion of reference. Whether such an amendment would be congenial to his general outlook, however, I cannot discuss here.

Finally, Salis also seems to misunderstand my claim about (1) and (2) being material equivalent. He writes, "The explanation, according to Båve, does not work in terms of anaphoric dependence: It works in terms of 'material equivalence' between two sentences, and no proform works in this way for the example above". But I did not attribute to Brandom any view at all about the material equivalence between (1) and (2). I merely said they are materially equivalent. This is not related to my objection that Brandom's theory makes 'true' different from other proforms. 
Let us now turn to Salis's objections against my main critique of (PT) (both the original version and Brandom's). My point was the following: that certain sentences containing 'true' are equivalent with, are consequences of, or entail, other sentences, is part of the linguistic data that a theory about 'true' should explain. One of the data, for instance, is that 'What John said is true', 'John said that snow is white' jointly entail, 'Snow is white'. But since talk of anaphoric relationships can be cashed out in terms of such relations as equivalence or consequence, or other "general semantic notions", the claims made by (PT) will merely "re-describe" the data, rather than explain them. Salis objects against this, claiming that the equivalence between two sentences may well be explicable by appeal to an anaphoric relation between them. He also suggests that the notion of anaphoric dependence can be taken as primitive and that the notions of equivalence and consequence are taken as derivative, as explained in terms of anaphoric dependencies.

On one reading, however, this cannot be right (and Salis surely didn't mean it this way). Surely, not all cases of equivalences or consequence can be explained in anaphoric terms. Consider,

John is a bachelor $\Rightarrow$ John is male

$\mathrm{A}$ and $\mathrm{B} \Rightarrow \mathrm{A}$

If these cases of consequence were to be explained by recourse to anaphoric dependencies, the latter notion would have to be stretched beyond recognition. (Indeed, one of my main complaints against Brandom was precisely that he overstretches the notions of anaphoric dependency, antecedent, etc., although perhaps not as blatantly.)

When claiming that the notions of equivalence and consequence are more general than that of anaphora, I had the above kind of case in mind: we need to appeal to these notions in our semantic theory anyway, but we need not necessarily appeal to any primitive notions of anaphoric dependency. Thus, in a choice of primitives, we should opt for equivalence and consequence, rather than anaphoric dependency. All cases of the latter kind can be "explained" in terms of the former, but not vice versa. When I say that anaphoric relations can be "explained" in terms of equivalence, I do not mean to say that we can explain why one thing anaphorically cross-refers to another by saying, "because so and so are equivalent". Rather, I mean that in order to define the notions of pronoun, antecedent, and similarly anaphoric notions, we must use the notion of equivalence, or some other more general semantic notion, like "sameness of content".

This should be rather obvious. Surely, we want to say that a pronoun is the kind of expression that inherits its content from another expression (its antecedent), or an expression due to which the sentence in which it occurs becomes equivalent with some other sentence, or some such. (Salis himself seems to suggest something like this.) But if we do so, anaphoric notions are no longer primitive, but explained in terms of sameness of content. This is in line with the claim I made in my original paper, that anaphoric phenomena should be explained in more general semantic terms.

Salis is nevertheless right, I think, that cases of equivalence can be explained by appeal to anaphoric relationships (e.g., that between a token of 'She is happy' and 'Mary is happy', where 'she' cross-refers to 'Mary'). Thus, there is another sense in which claims of equivalence or sameness of content are indeed posterior to claims about anaphoric relationships. For this reason, my original claim that (PT) merely re-describes the data is inaccurate. 
But I think the gist of my original critique is still cogent, although the point must be made more carefully. I spoke as if the following are synonymous:

(a) $\mathrm{A}$ is the anaphoric antecedent of $\mathrm{B}$

(b) A and B have the same content

But they obviously aren't, since there are expressions which have the same content but do not involve anaphora. This means that it was misleading at best to say that prosententialists merely "re-describe the data". This also connects with the issue of explanatory primacy. If the sentences above were synonymous, one could complain that explaining why two sentences are equivalent by recourse to an anaphoric dependency between them would be circular: replacing the anaphoric notions in the explanation by their definientia would result in something like:

“ 'John is happy' is true" is equivalent with (or: has the same content as) 'John is happy' because " 'John is happy' is true" is equivalent with (or: has the same content as) 'John is happy'.

Here, 'is the anaphoric antecedent of' is replaced in the right-hand side of 'because' by 'is equivalent with' (or 'has the same content as').

So, I agree with Salis that one can explain why the sentences below are equivalent by recourse to anaphoric dependencies:

Mary is happy

She is happy [where the antecedent of 'she' is 'Mary']

Thus, the real problem with (PT) isn't quite that it merely re-describes the data. The real problem becomes apparent, however, if we replace the anaphoric terminology with the relevant definientia, using the right definition. I take the following to be a more plausible definition of 'being the antecedent of':

$\mathrm{A}$ is the (anaphoric) antecedent of $\mathrm{B}={ }_{\mathrm{df}} \mathrm{B}$ is a token expression which, due to a convention governing the type to which B belongs (e.g., the type 'she'), acquires the content of B because B stands in $\mathrm{R}$ to $\mathrm{A}$ in the context in which $\mathrm{B}$ is tokened.

Here, $\mathrm{R}$ is the relation holding between two token expressions in a context in virtue of which one is the antecedent of the other in that context. We need not dwell on this relation, which is a matter of controversy. $\mathrm{R}$ might be defined in terms of speakers' and hearers' intentions, in terms of relevance or salience, or some other way. Anyone should agree that there must be something that accounts for one token expression being the antecedent of a given token proform, even if neither of the two examples just given fits the bill.

Assuming that the definition above is at least along the right lines, we can see more clearly what is wrong with (PT). The problem is that the theory might as well have been formulated without using the notion of anaphora, and instead, more directly, by appeal 
to the more general semantic notions used in the definiens above. That is, 'true' could have been characterized as an expression due to which sentences in which it occurs inherit their contents (or become equivalent with) certain other sentences, namely, those to which they stand in relation $\mathrm{R}$.

This account would of course have to be further specified in order to handle the different ways in which 'true' can occur in sentences, but those complications may be set aside here. My point was that anaphoric notions like "antecedent" become idle if they can be replaced by more general semantic notions, as suggested here. And we have now seen that this point can be made without making the implausible claim that (a) and (b) are equivalent, or that (PT) merely "re-describes the data".

One of my original points was that if the workings of 'true' could be accurately described using the terms, 'proform', 'antecedent', etc., then that description would be idle in the sense that an equally accurate description may as well have been given without appeal to anaphoric notions, but rather in more general semantic terms. I expressed this point by saying that there is nothing "essentially proformal" about 'true'.

A separate and independent question is whether one can indeed accurately describe the workings of 'true' in anaphoric terms. To this, I responded in the negative, and supported this answer by appeal to the many discrepancies between the relevant sentences containing 'true' and sentences containing uncontroversial examples of anaphoric expressions. And we have just seen that Salis's objection against one of these alleged examples, concerning (1) above, fails. My point about the dissimilarities between 'true' and paradigmatic proforms thus stands: the workings of 'true' cannot be accurately described using terms like 'proform' and 'antecedent', at least not in any way resembling the way in which the original prosententialists or Brandom did it.

I also took these discrepancies to be relevant for answering a further question. I asked what 'true' would have to be like in order for the analogy with paradigmatic proforms not to be idle, and answered that it would have to bear striking, unexpected resemblances with paradigmatic proforms, consisting in shared idiosyncrasies, etc. (2009a: 308). But the discrepancies between the two types of expression of course undermine this possibility, too. The word 'true' and paradigmatic proforms do not share many unexpected features, for they do not share many features at all.

Considering the specific example of utterances of 'That's true', made in response to a preceding utterance, is there at least something anaphoric about them? I think not. At any rate, it is definitely not obvious that there is. The most natural analysis takes 'that' here to be a demonstrative (cf. Künne (2003: 78f.)). Typically, it would refer to the proposition expressed by the preceding utterance, since that will typically be the most salient entity that can be true. Given the standard propositional truth equivalence schema, we can then straightforwardly explain why 'That is true' comes to be equivalent, on this occasion, with the preceding utterance. Hence, standard Horwichian deflationism handles this type of case without any unobvious appeal to anaphora. (Note also that Brandom himself distinguishes between demonstrative reference to a non-linguistic entity and anaphoric cross-reference to a linguistic one (1994: 456), so he cannot say that the above treatment of 'That is true' conforms to his anaphoric account.)

Brandom does claim, however, that demonstrative reference is a kind of anaphoric reference (1994: 460), and takes demonstratives to presuppose anaphora (1994: 460, 511). However, this does not affect my point that 'That is true' is not an obvious case of an anaphoric expression. For that claim is not immediately obvious by itself, and 
neither is Brandom's view about the relationship between demonstratives and anaphora. Thus, my point stands, even lacking an argument against Brandom's claims about demonstratives being a kind of anaphora.

Let me also add a further difference between 'true', as Brandom treats it, and paradigmatic proforms. Other proforms are, so to speak, purely proformal; they do not contain material that is not proformal. Consider, 'he', 'thusly', 'so'. But 'true' is supposed to be a mere part of the relevant proform (a prosentence), which can contain all manner of non-proformal expressions, like 'Goldbach's conjecture', 'Everything he said', or 'that snow is white'. On Brandom's view, these other expressions help determine the antecedent. But other proforms simply do not work this way. They immediately cross-refer back to their antecedents without any detour through other expressions (and, again, certainly not in virtue of other expressions' denoting the antecedents).

Let us finally consider Salis's positive defence of (PT). He writes, "we should not forget that the anaphoric theory is also explanatorily more general [than a theory merely stating the equivalence schema] because it also explains pragmatic and expressive differences between anaphoric antecedents and prosentences" (2019: 519). Against this, I would claim, firstly, that (PT) does not explain the pragmatic features of 'true'. The relevant "pragmatic" features of 'That's true', uttered in response to some claim, are supposed to include,

[e]xpressing this claim, distinguishing the endorsement of this claim from the rejection of other claims, acknowledging what was said, doing it with less resources and avoiding the repetition of what was said, and many others-but there is also a general expressive difference. Prosentences are, in general, expressively more powerful than the corresponding sentences (2019: 509).

However, as far as I understand these alleged properties of the relevant utterances, they are not clearly "explained" by (PT). Many of them are properties one can easily observe independently of any anaphoric theory of 'true', and these observations could be added to any theory of 'true'. Consider, for instance, the fact that 'That is true' "acknowledges an antecedent", a feature that would have been absent if the preceding utterance had merely been repeated (cf. Brandom 1994: 302). But the observation that 'That's true' refers to something extraneous is just independently obvious. It is not somehow derived from (PT), it can be made independently of (PT), and it can be added to any theory about 'true'.

It may be objected that the above way of accounting for how the utterance "acknowledges an antecedent" fails, if the latter notion is by definition something involving an anaphor. On the other hand, if so taken, it would be question-begging to demand of other, non-anaphoric theories of 'true' that it explain the feature (so understood). The uncontroversial datum is merely that "something extraneous is acknowledged", and this datum can be accommodated on other theories, given the analysis of 'That's true' as containing a demonstrative.

As for expressive strengthening, it is not clear, firstly, that this feature can be explained by (PT). However, it can clearly be explained on the basis of a simple deflationist theory that takes the meaning of 'true' to be exhaustively given by the claim that it is introduced via the trivial equivalence between 'that $p$ is true' and the 
corresponding ' $p$ ' (cf. Båve (2006: 139f.), (2009b: §4), and (2015)). This simple theory also arguably has the resources to explain the meaning of all the different uses of 'true', together with independent assumptions (see Båve (2006: Ch. 4) and (2010)). Thus, given that it scores higher with respect to clarity, explanatory scope, and simplicity, and given how it avoids the various problems we have found with (PT), it is preferable.

Open Access This article is distributed under the terms of the Creative Commons Attribution 4.0 International License (http://creativecommons.org/licenses/by/4.0/), which permits unrestricted use, distribution, and reproduction in any medium, provided you give appropriate credit to the original author(s) and the source, provide a link to the Creative Commons license, and indicate if changes were made.

\section{References}

Båve, A. (2006). Deflationism: A use-theoretic analysis of the truth-predicate. Stockholm: Almqvist \& Wiksell International.

Båve, A. (2009a). Why is a truth-predicate like a pronoun? Philosophical Studies, 145, 297-310.

Båve, A. (2009b). A deflationary theory of reference. Synthese, 169, 51-73.

Båve, A. (2010). Deflationism and the primary truth-bearer. Synthese, 173, 281-297.

Båve, A. (2015). A deflationist error theory of properties. Dialectica, 69, 23-59.

Brandom, R. (1994). Making it explicit. Cambridge, MA: Harvard University Press.

Grover, D., Camp, J., \& Belnap, N. (1975). A Prosentential theory of truth. Philosophical Studies, 27, $73-125$. Künne, W. (2003). Conceptions of truth. Oxford: Clarendon Press.

Salis, P. (2019). The generality of anaphoric deflationism. Philosophia, 47, 505-522.

Publisher's Note Springer Nature remains neutral with regard to jurisdictional claims in published maps and institutional affiliations. 